Nevertheless, in this instance there does seem to be the possibility that the data reported in our papers have significance to the clinical observation of Cohen \& Lawton.

GREeN, A. R. \& MOUNTFORD, J. A. (1985) Diazepam administration to mice prevents some of the changes in monoamine mediated behaviour produced by repeated electroconvulsive shock treatment. Psychopharmacology, 86, 190-193.

- \& NUTT, D. J. (1987) Psychopharmacology of repeated seizures: possible relevance to the mechanism of action of electroconvulsive therapy. In Handbook of Psychopharmacology (eds L. L. Iversen, S. D. Iversen \& S. H. Snyder), 19, 375-419.

Astra Neuroscience Research Unit

A. RICHARD GREEN

1 Wakefield Street

London WCIN IPJ

\section{Drug therapy of post-traumatic stress disorder}

SIR: We feel concerned that Davidson's comprehensive review of the drug therapy of post-traumatic stress disorder (PTSD) (Journal, March 1992, 160, 309-314) may serve to encourage those unfamiliar with the condition to consider medication as the first line of treatment. The studies reviewed suggest medication may help, but some of the benefits can probably be accounted for by the treatment of a coexisting depressive disorder rather than the treatment of PTSD per se.

Fairbank \& Nicholson (1987) reviewed dynamic, behavioural and biochemical models of treatment and found that direct therapeutic exposure appeared to emerge as the single most important factor in the treatment of PTSD. Richards \& Rose (1991) described rapid, effective therapy with a combination of in vivo and imaginal exposure in four cases of longstanding and severely debilitating PTSD.

We too are experiencing rapid improvement in PTSD sufferers using audiotaped imaginal exposure without concomitant medication, even in those with marked symptoms of hyperarousal.

We agree with Davidson's call for more formal research into the behavioural treatment of PTSD and comparative and interactive studies of it and pharmacotherapy. We also acknowledge that there is a lack of empirical data relating to the treatment of PTSD with exposure therapy. However, with the present body of knowledge and the acceptability of exposure therapy to the patient, we feel it should be used as the first-line treatment in PTSD, with medication being reserved as second line or used to treat a coexisting problem such as depressive disorder.
Fairbank, J. A \& Nicholson, R. A. (1987) Theoretical and empirical issues in the treatment of post-traumatic stress disorder in Vietnam veterans. Journal of Cinical Psychology, 43, 44-55.

Richards, D. A. \& Rose, J. S. (1991) Exposure therapy for posttraumatic stress disorder. Four case studies. British Journal of Psychiatry, 158, 836-840.

JONATHON I. BISSON NORMAN JONES

Department of Psychiatry

\section{$B M H$ Iserlohn}

BFPO 24

\section{Acute transient stress-induced hallucinations in} soldiers

SIR: The most likely explanation of the pseudohallucinations in the three frightened recruits (Journal, March 1992, 160, 414-416) is that they were hypnagogic phenomena. It is a pity that Dr Spivack and his colleagues do not mention this in their discussion which deals exclusively and very well with content but not with form. The thoughts described were no doubt going through the minds of the soldiers, but why in the form of pseudohallucinations?

These phenomena are common in ordinary psychiatric practice. They are often left unexplained or may even lead to an incorrect diagnosis, but if you ask about the circumstances in which they occurred you often find that the patient was sitting alone in a comfortable armchair, perhaps in front of the television, or was in bed, so there is a reasonable presumption that he may briefly have dropped off to sleep. The paper tells us that each patient was alone but does not say in what circumstances although the large ants in case 1 should have given the authors the clue to ask.

The paper refers to similar phenomena in so-called post-traumatic stress disorder (PTSD). Alcohol consumption is high in these patients (Wilson, 1988), which probably accounts for a great deal of their anxiety; the subjects may also be more likely to fall asleep than otherwise or may be experiencing the warning symptoms of delirium tremens.

The "common underlying mechanism" is thus anxiety which accounts both for the anxiety-laden thoughts and for the disruption of the normally smooth process of falling asleep. There may be an additional toxic mechanism if the patient is drinking.

WILSON, G. T. (1988) Alcohol and anxiety. Behaviour Research Therapy, 26, 369-381.

8 Linnell Drive

Samuel I. Cohen 